\title{
GOAL ANALYSIS OF THE ENTIRE ITALIAN NATIONAL LEAGUE SERIE A
}

original paper

() Wroclaw University of Health and Sport Sciences

DOI: https://doi.org/10.5114/hm.2021.106172

\section{CHARALAMPOS BAMPLEKIS ${ }^{1}$, YIANNIS MICHAILIDIS ${ }^{1}$, KONSTANTINOS MARGONIS ${ }^{2}$, AGGELOS KYRANOUDIS ${ }^{2}$, CHARALAMBOS ZELENITSAS ${ }^{3}$, THOMAS METAXAS ${ }^{1}$}

${ }^{1}$ Laboratory of Evaluation of Human Biological Performance, Department of Physical Education and Sport Science,

Aristotle University of Thessaloniki, Thessaloniki, Greece

${ }^{2}$ Department of Physical Education and Sport Science, Democritus University of Thrace, Komotini, Greece

${ }^{3}$ Section of Sport Medicine and Biology of Exercise, School of Physical Education and Sport Science,

National and Kapodistrian University of Athens, Athens, Greece

\section{ABSTRACT}

Purpose. The purpose of this study was to analyse the goals in soccer Italian League Serie A (2018-2019) in relation to (a) the number of total attempts; (b) the time reached; (c) the area from which the final action occurred. Also, the effect of achieving the first goal in the match outcome was studied.

Methods. A total of 380 matches were studied, with 1019 goals scored. All matches were analysed with the SportScout software. Chi-square test was used to find differences between the display frequencies of each variable.

Results. More goals were scored in the second half of the match $\left(\chi^{2}=25.438, p<0.05\right)$ and in the last 15 minutes. Most goal attempts were made through the penalty box and outside of it $\left(\chi^{2}=2365.002, p<0.05\right)$, though the highest success rates were shown in the attempts from the goal box. Overall, $30 \%$ of the total number of goals were scored from set plays $\left(\chi^{2}=171.493, p<0.05\right)$, most of them after a corner shot $\left(\chi^{2}=18.488, p<0.05\right)$. Furthermore, it appeared that the first goal had a strong impact on the final outcome since in $67.34 \%$ of the cases, the team that scored first won the match.

Conclusions. More goals were scored in the second half, especially in the last 15 minutes. Coaches should prepare their players to be fit to cope with the whole match. They will also need to improve their defensive and offensive tactics in set plays. Key words: Italian League Serie A, goal, video analysis, time period, set play

\section{Introduction}

Soccer is one of the most popular sports in the world. At the beginning of the $21^{\text {st }}$ century, more than 250 million athletes were registered, while more than 1.3 billion people were involved in the sport [1]. Match analysis is vital in team sports in order to understand the constraints that promote sporting success [2]. Performance in soccer depends on many factors that interact with one another, such as technique, tactics, and fitness [3]. Match analysis is used to identify the strengths and weaknesses of teams and players in order to improve their performance [4].

Research on international soccer has shown that coaches could only remember $42 \%$ of the corrections they had to make during a match [5]. These studies indicate that human memory may not be very reliable for feedback of an event or a match [5]. In turn, an objective assessment derived from video analysis offers, as much as possible, analytical, realistic, and more accurate information illustrating the performance profile of the team and players in real game conditions [6].

One of the most studied variables is the goal because it is critical for the success of a team [4]. Previous studies have reported that the number of goals achieved varies depending on the time of the match $[7,8]$, with more goals obtained in the second half. Also, if we divide the 90 minutes of the game into periods of 15 minutes, the most goals were scored in the last period $\left(76-90^{+} \mathrm{min}\right)[7,9,10]$. Other factors re-

Correspondence address: Yiannis Michailidis, Laboratory of Evaluation of Human Biological Performance, Department of Physical Education and Sport Science, Aristotle University of Thessaloniki, New Buildings of Laboratories, P.O. 57001, University Campus of Thermi, Thessaloniki, Greece, e-mail: ioannimd@phed.auth.gr

Received: November 7, 2020

Accepted for publication: February 8, 2021

Citation: Bamplekis C, Michailidis Y, Margonis K, Kyranoudis A, Zelenitsas C, Metaxas T. Goal analysis of the entire Italian National League Serie A. Hum Mov. 2022;23(2):104-111; doi: https://oi.org/10.5114/hm.2021.106172. 
Table 1. Terms and definition

\begin{tabular}{|c|c|}
\hline Term & Definition \\
\hline Goal & The ball crosses the goal line under the crossbar and the referee awards it \\
\hline Goal attempt & Kick the ball to the goalpost without the ball being blocked \\
\hline Free kick & Set play after foul from the opposition, outside penalty box [17] \\
\hline Penalty kick & Set play after foul from the opposition, inside penalty box [17] \\
\hline Corner kick & $\begin{array}{l}\text { The ball is restored from the corner of the field when an opponent last touched the ball and it crossed } \\
\text { the goal line [17] }\end{array}$ \\
\hline Pass & A player passes on to a teammate and the ball reaches its destination \\
\hline Open play & The ball moves and can be claimed by both teams \\
\hline Set play & Used to get the ball back to a state of open play after foul, corner, penalty [18] \\
\hline
\end{tabular}

lated to goal are being studied, such as the type and area of the action prior to a goal, the effectiveness of the team, etc. $[8,11]$.

Another important factor in the performance of a soccer team is the effectiveness in set plays, both in the attack phase and in the defence phase $[12,13]$. Other factors have also been studied, such as the effect of the first goal of a match on the final match outcome $[8,11,14,15]$ and the place of the match (home or away) [16]. Although there are several studies on the technical and tactical characteristics of national teams participating in world and European tournaments, research on full national championships is more limited.

The purpose of this study was to analyse all the national competition goals in soccer Italian League Serie A in relation to (a) the number of total attempts; (b) the time reached; (c) the area from which the final action occurred. The place of the match (home or away) and the effect of achieving the first goal on the match outcome were also investigated. It was hypothesized that (a) goal scoring frequency was higher in the second half; (b) most goal attempts were made through the penalty box; (c) most goals were scored from open plays; and (d) the first goal had a strong impact on the final outcome.

\section{Material and methods}

\section{Sample}

A total of 380 matches of the Italian League Serie A were analysed. Overall, 1019 goals were scored and 7723 final actions (attempts for goals) were performed. These matches were played by 20 teams that participated in the championship during the season of 20182019.

\section{Instrument}

The soccer matches were videotaped and digitized with a Sony video SLV-SE210D, a PC AMD-XP professional $1333 \mathrm{GHz}$, and a television capture board for PC (PCTV, Pinnacle Systems GmbH, Braunschweig, Germany). The study was based on the personal observation of one of the researchers, who recorded the time when goals were scored. The SportScout (SportScout STA) video-analysis program for PC was used for the data recording. The operational definitions applied are presented in Table 1.

\section{Procedures}

The SportScout software (SportScout STA) allowed to analyse the number of goals per half and every 15 minutes ( 6 periods: $1-15 \mathrm{~min}, 16-30 \mathrm{~min}, 31-45^{+}$ min, 46-60 min, 61-75 min, 76-90 $\mathrm{min}$ ) [19], whether the goal came in the open play or from a set play, and the effect of the first goal on the match outcome. Also, the number of goals, penalties, own goals, and counterattacks of home and visitor teams were recorded. The spaces outside and inside the penalty box and inside the goal box were these 3 spaces to distinguish the final actions for goals.

\section{Reliability}

To determine the reliability in data recording, the first author of the article recorded all variables from 3 matches. A certified football analyst did the same. The comparison of the data that emerged showed that the recordings of the first author were very reliable. The values of kappa statistic $(r)$ test were between 0.97 and 1, i.e. particularly high according to Altman [20]. More specifically:

- the $r$ for the number of goals per half and every 15 minutes was 1 ; 


\section{HUMAN MOVEMENT}

C. Bamplekis et al., Goal analysis

- the $r$ for whether the goal came in the open play or from a set play was 0.99 ;

- the $r$ for the number of goals, penalties, own goals was 1 ;

- the $r$ for the counter-attacks of home and visitor teams was 0.97;

- the $r$ for spaces outside and inside the penalty box and inside the goal box that were the 3 spaces to distinguish the final actions for goals was 0.98 .

\section{Statistical analysis}

The statistical software SPSS 18 (IBM, SPSS Statistics, version 18, Armonk, NY, USA) was used for data analysis. Apart from descriptive statistics, the chi-square test $\left(\chi^{2}\right)$ was applied to find differences between the display frequencies of each variable, as well as the effect of the first goal on the match outcome. Statistical significance of the results was accepted at $p<0.05$.

\section{Ethical approval}

The conducted research is not related to either human or animal use.

\section{Results}

Goals frequency of each half is presented in Figure $1 \mathrm{~A}$. The results show that there were significant differences in the number of goals scored between the 2 halves $\left(\chi^{2}=25.438, p<0.05\right)$. In the first half, $42.1 \%$ of goals were scored, and $57.9 \%$ of goals were scored in the second half.

Figure $1 \mathrm{~B}$ depicts the frequency of the appearance of goals in the 6 match periods of 15 minutes. Differences in the frequency of goals occurred between the $6^{\text {th }}$ period (76-90 minutes) and all the other periods $\left(\chi^{2}=50.631, p<0.05\right)$. It was found that most goals were scored at the end of the match $(22.6 \%)$, at the beginning of the second half (18.2\%), and at the end of the first half (18\%).

Most goals (698) were scored during open play, while 287 goals during set play $\left(\chi^{2}=171.493, p<0.05\right)$. Figure 2A shows the differences in frequency by the type of goal. As for counter-attacks, the home teams made 7801 while the visitor teams 7053 . These variables are presented in Figure 2B.

Figure $3 \mathrm{~A}$ shows the frequencies of final actions depending on the space where they occurred. Most final actions were performed in the penalty box and outside the penalty box $\left(\chi^{2}=2365.002, p<0.05\right)$. Home teams performed $48.4 \%$ of their final actions through
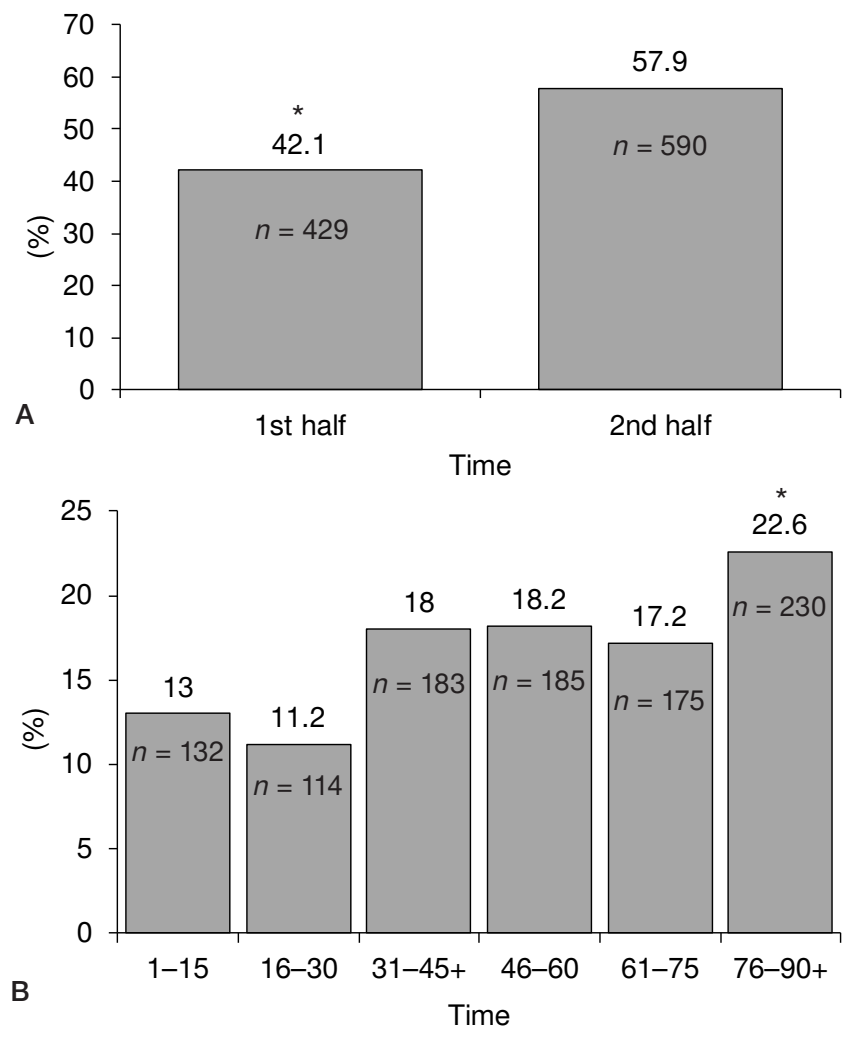

* significant difference with other groups $(p<0.05)$

Figure 1. Frequency of goals: (A) in the game halves,

(B) in the 15-minute periods
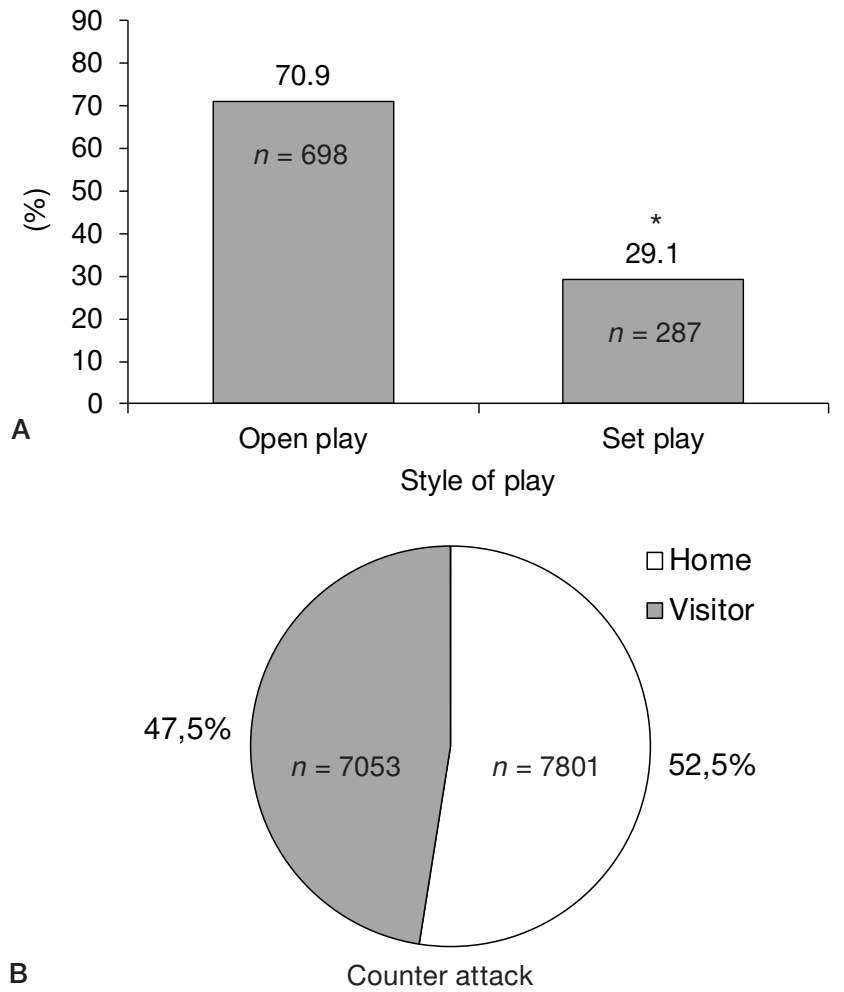

* significant difference with other groups $(p<0.05)$

Figure 2. (A) Percentages of open play and set play goals (B) Numbers of counter-attacks of home and visitor teams 

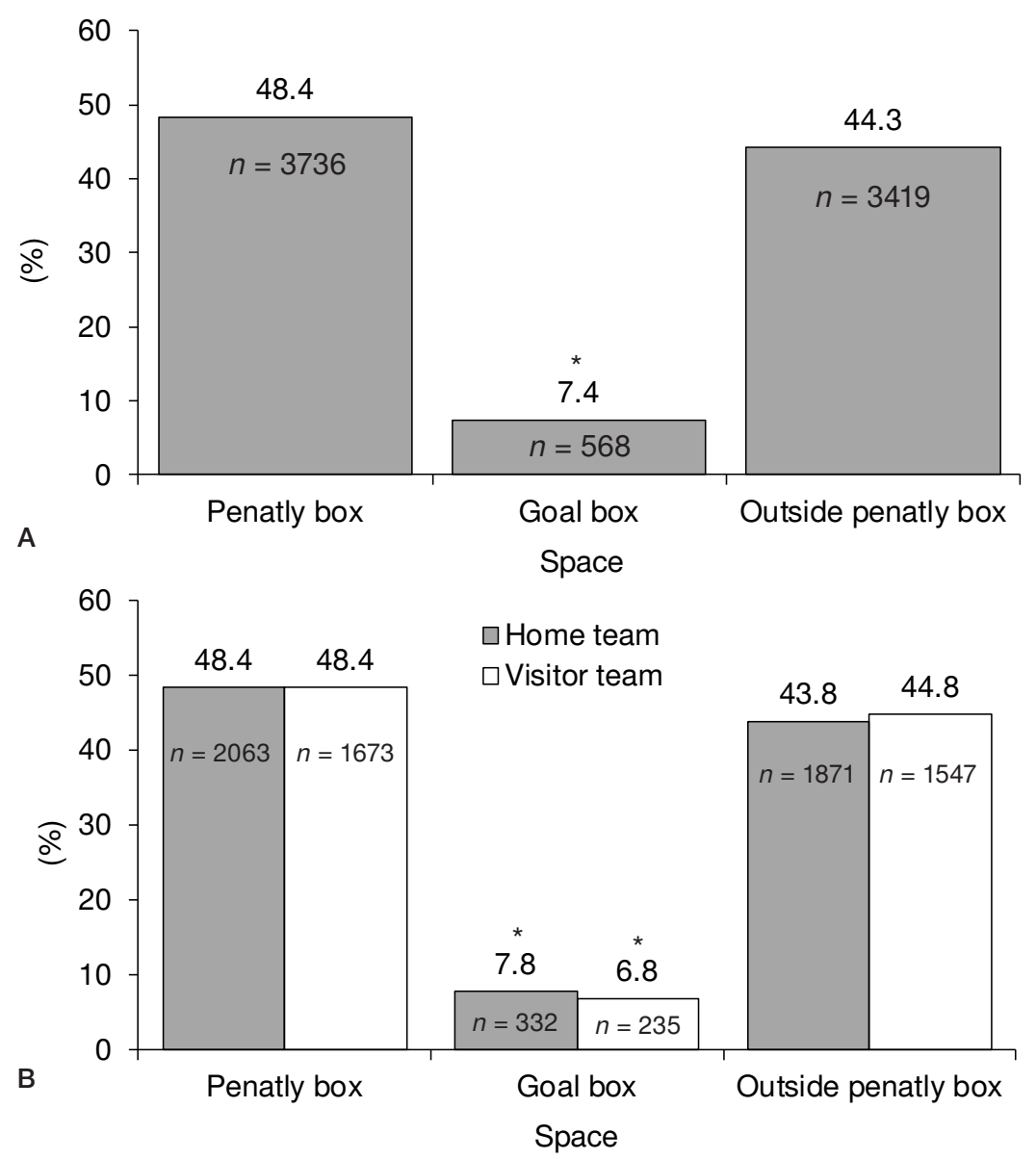

\section{* significant difference \\ with other groups $(p<0.05)$}

Figure 3. (A) Space of final actions

(B) Space of final actions of home and visitor teams

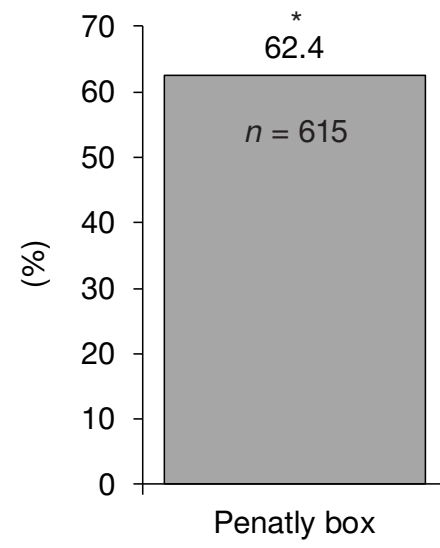

A

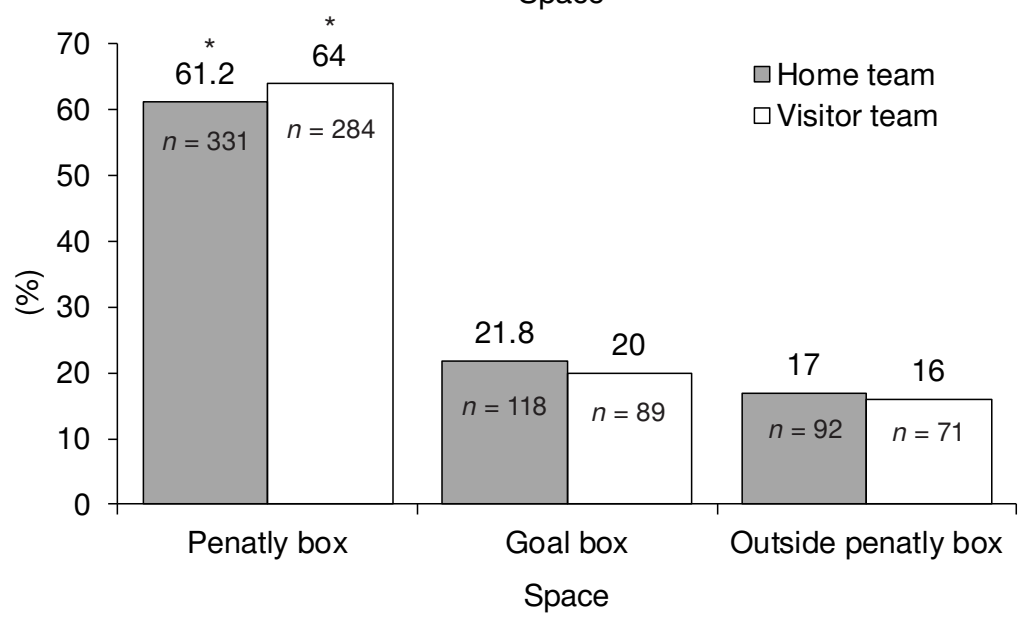

16.6

$n=207 \quad n=163$

Goal box Outside penatly box 


\section{HUMAN MOVEMENT}

C. Bamplekis et al., Goal analysis

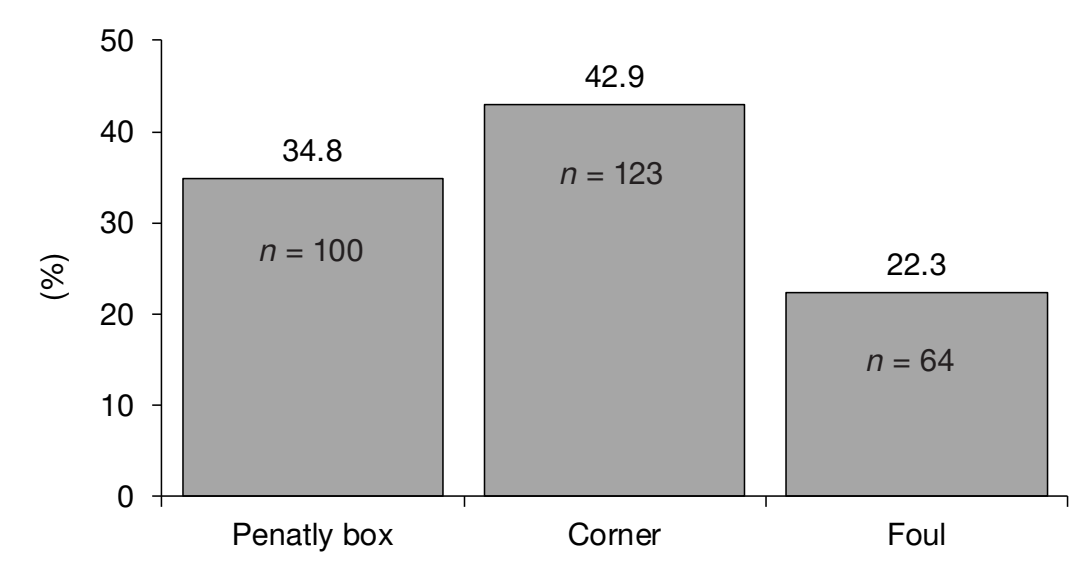

A

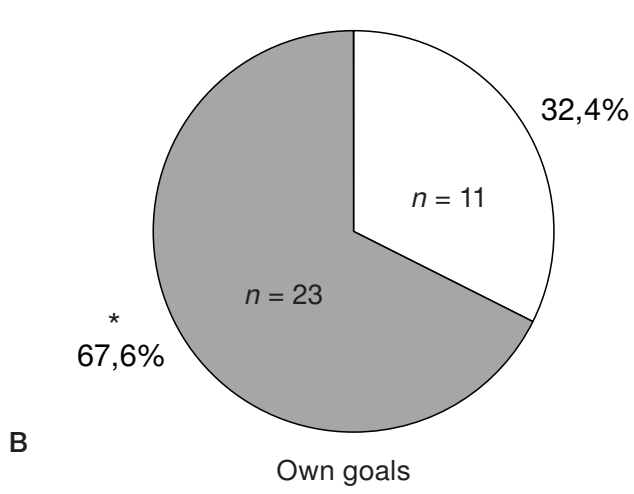

Set play category

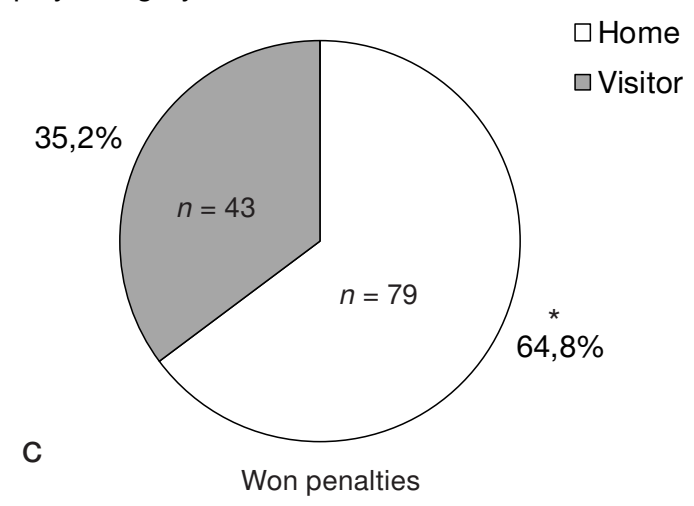

* significant difference with other groups $(p<0.05)$

Figure 5. (A) Set play goals

(B) Percentage of own goals of home and visitor teams

(C) Percentage of won penalties of home and visitor teams

the penalty box, $43.8 \%$ outside the penalty box, and $7.8 \%$ through the goal box $\left(\chi^{2}=1266.232, p<0.05\right)$. The respective percentages for visitor teams were $48.4 \%, 44.8 \%$, and $6.8 \%\left(\chi^{2}=1101.321, p<0.05\right)$. Figure $3 \mathrm{~B}$ shows the frequency of goal attempts and goals from each field area for the home team and visitor team.

Overall, $62.4 \%$ of goals were scored from the penalty box, 21\% from the goal box, and 16.6\% from outside the penalty box $\left(\chi^{2}=378.380, p<0.05\right)$. Home teams scored $61.2 \%$ of their goals from inside the penalty box, while the corresponding percentage for visitor teams was $64 \%$. Home teams scored $21.8 \%$ of their goals and visitor teams $20 \%$ of theirs through the goal box, whereas the respective percentages for outside the penalty box were $17 \%$ and $16 \%$. Differences were observed in both home teams $\left(\chi^{2}=190.695, p<\right.$ $0.05)$ and visitor teams $\left(\chi^{2}=188.554, p<0.05\right)$. The frequency differences are shown in Figure 4A, B.

The results show that home teams won more penalties (79) than visitor teams (43) $\left(\chi^{2}=10.623, p=\right.$ $0.001)$. Also, home teams scored fewer own goals (11) than visitors (23) $\left(\chi^{2}=4.235, p=0.04\right)$. In set plays, most goals were scored after corners (123) and penalties (100) compared with fouls (64) $\left(\chi^{2}=18.488\right.$, $p<0.05)$. The above frequencies are presented in Figure 5A-C.

The study revealed that for the 195 occasions where home teams scored first, they won 143 matches, while for the 151 occasions where visitor teams scored first, they won 90 matches $\left(\chi^{2}=240.9, p<0.05\right)$.

\section{Discussion}

The main objectives of the research were to analyse the goals in soccer Italian League Serie A (20182019) in relation to (a) the number of total attempts; (b) the time reached; (c) the area from which the final action occurred. Also, with regard to the place of the match (home or away), goals, attempts to score, and the effect of achieving the first goal on the match outcome were studied. A difference was observed in the frequency of goals scored in relation to the time (match halves, 15-minute periods) and the area from which most final actions were performed. Moreover, differences were found in the frequency of goals between 
open play and set play. Finally, there were differences between home teams and visitor ones in the number of goals scored and in penalties that they won.

The results imply that more goals were scored in the second half than in the first half. This finding is in line with previous studies carried out in both national leagues [19] and international tournaments involving national teams $[14,15,21,22]$. The difference is also reflected in the 15-minute periods, where the periods of the second half presented higher frequencies of goals than those in the first half. A high frequency of goals in the $76-90^{+}$period has also been reported in previous studies [7, 8, 19, 21, 23].

A goal depends on many factors. So, one cannot accurately point out the cause of this phenomenon. The tactics of the team that is behind the scoring, the tactics of the winning team, the physical and mental fatigue, lack of concentration are all factors that can affect the achievement of more goals in the last minutes of a match. However, in previous studies, it has been reported that fatigue as well as its effect on the concentration of defenders may be an important factor in the emergence of more goals at the end of a match [24]. Similar results were mentioned in a recent study that analysed goals in the English Premier League [19]. More specifically, previous studies have shown that defenders cover shorter distances with high intensity in the last 15 minutes compared with the first 15 minutes, while the corresponding drop for forwards is smaller [25]. Also, it has been reported that fatigue can affect the correct decision making during matches [26]. With these 2 factors, the strikers who find more space to perform their final action seem to be favoured during open play [27].

As far as the area of the final action is concerned, differences were noted with most attempts performed in (48.4\%) and outside (44.3\%) the penalty box and the least through the goal box (7.4\%). Similar percentages were presented for home teams $(48.4 \%, 43.9 \%$, and $7.8 \%$, respectively) and for visitor teams $(48.4 \%, 44.8 \%$, and $6.8 \%$, respectively).

With reducing the distance of the final action from the goalpost, the chance of scoring a goal increased. However, as the opponent approaches the focus, defenders restrict spaces so that it was very difficult for forwards to enter the goal box. Also, when a forward is inside the penalty box, he believes that he is close enough to the goalpost to perform a final action (like a shoot). As the distance from the goalpost increases, the effectiveness of players decreases, though the defence is less pressing, allowing for more final actions. The above fact is reflected in the percentage of goals scored (effectiveness) from the different field areas, with the highest percentage in actions through the goal box (36.4\%), followed by actions from the penalty box (16.5\%), followed by goals from outside the penalty box (4.8\%). Similar percentages were shown for home teams (35.5\% for goal box, $16.0 \%$ for penalty box, and $4.9 \%$ for outside the penalty box) and visitor teams (37.9\%, $17.0 \%$, and $4.6 \%$, respectively).

Goals scored from open play constituted $70.9 \%$ of the total number of goals. This percentage is similar to those reported in previous studies on the English Premier League [28]. Watching over time, it is found that the percentage of goals scored by open play moves close to $70 \%$. This indicates that a very significant part of the total number of goals are scored by set plays. This suggests that coaches should pay particular attention to the offensive and defensive function of their players during set plays.

Of goals scored during set plays, $42.9 \%$ came from corners, $34.8 \%$ from a penalty shootout, and $22.3 \%$ from fouls. On this basis, it appears that the corner is the most dangerous set play as it resulted in almost twice as many goals scored as compared with fouls. High goal scoring rates from the corner were also mentioned in previous studies [29]. To interpret this observation, we should consider that during corners, forwards occupy spaces in very dangerous positions in front and near the goalpost, so defenders cannot take advantage of the regulation of offside. In turn, in many cases of fouls, defenders take advantage of the regulation of offside by keeping the opposing forwards at a long distance from their goalpost, thereby reducing the chance of conceding a goal. However, in order to get an accurate picture, we need to know the total number of corners and fouls executed by the teams to estimate the effectiveness of each set play.

Among the total number of penalties, $64.8 \%$ were given to home teams and the remaining $35.2 \%$ to visitor teams. Home teams also scored 11 own goals, while visitors scored 23 own goals. The above percentages reflect particularly the pressure that home teams put on visitor teams to receive a positive match outcome. Teams competing at home, with the encouragement of their fans, probably put more pressure on visitors, forcing them to fall into the penalty shootout or score an own goal. Although we would expect visitor teams to show a higher counter-attack rate per match in this league, it was found that the average number of counter-attacks per match was 20.5 for the home team and 18.6 for the visitor team. Counter-attack can be not only a method for a team's building up in specific match situations, but also the basic offensive tactic of 
a team, especially when it competes against a higher level team.

Finally, the results showed that the team that scored the first goal gained significant advantage in winning the match, as it was indicated in $73.33 \%$ of the cases in which home teams scored first goals and in 59.6\% of the cases in which visitor teams scored the first goal, eventually winning the match. A similar effect of the first goal on the match outcome has been reported in previous studies $[8,11,14,15,22]$. When a team scores the first goal, there is an improvement in performance and the players present more self-confidence and passion [30, 31]. Moreover, tactical changes with more attention in defence were observed when a team was in the lead [32].

With regard to the limitations of the present study, our analysis was mainly focused on the last action prior to a goal, which means that other important actions of the whole attacking process were not explored. Additionally, variables like team tactics were not considered. This could be an aspect for future studies; capturing so many complex and interactive behaviours prior to a goal would require the use of multiple research methodologies.

\section{Conclusions}

The study results showed that in the Italian League Serie A, more goals were scored in the second half, especially in the last 15 minutes. Coaches should prepare their players to be fit to cope with the whole match. This will help players to act more effectively and not to be affected by fatigue. They will also need to improve their defensive and offensive tactics in set plays as $30 \%$ of the total number of goals is achieved in this way. One more thing to watch out for is that each team should seek to score the first goal as this can have a significant impact on the final match outcome. However, coaches have to prepare players to deal with a situation in which the opponent takes the lead. Finally, coaches should improve the efficiency of their teams outside the penalty box, probably enhancing both the technique and tactics for the correct selection of conditions for a final action.

\section{Disclosure statement}

No author has any financial interest or received any financial benefit from this research.

\section{Conflict of interest}

The authors state no conflict of interest.

\section{References}

1. Orejan J. Football/soccer: history and tactics. Jefferson: McFarland; 2011.

2. Carling C, Reilly T, Williams AM (eds.). Performance assessment for field sports. London: Routledge; 2009.

3. Stølen T, Chamari K, Castagna C, Wisløff U. Physiology of soccer: an update. Sports Med. 2005;35(6):501536; doi: 10.2165/00007256-200535060-00004.

4. Lago-Peñas C, Lago-Ballesteros J, Rey E. Differences in performance indicators between winning and losing teams in the UEFA Champions League. J Hum Kinet. 2011;27:135-146; doi: 10.2478/v10078-011-0011-3.

5. Hughes M, Franks I. Analysis of passing sequences, shots and goals in soccer. J Sports Sci. 2005;23(5):509514; doi: 10.1080/02640410410001716779.

6. Hohmann A, Rommel G. Match observation in football [in German]. Leistungssport. 1994;24(6):41-46.

7. Armatas V, Yiannakos A, Papadopoulou S, Skoufas D. Evaluation of goals scored in top ranking soccer matches: Greek “SuperLeague” 2006-07. Serb J Sports Sci. 2009;3(1):39-43.

8. Armatas V, Yiannakos A. Analysis and evaluation of goals scored in 2006 World Cup. J Sport Health Res. 2010;2(2):119-128.

9. Alberti G, Iaia FM, Arcelli E, Cavaggioni L, Rampinini E. Goal scoring patterns in major European soccer leagues. Sport Sci Health. 2013;9(3):151-153; doi: 10.1007/s11332-013-0154-9.

10. Njororai WSS. Timing of goals scored in selected European and South American soccer leagues, FIFA and UEFA tournaments and the critical phases of a match. Int J Sports Sci. 2014;4(6A):56-64; doi: 10.5923/s. sports.201401.08.

11. Michaildis Y, Michaildis C, Primpa E. Analysis of goals scored in European Championship 2012. J Hum Sport Exerc. 2013;8(2):367-375; doi: 10.4100/jhse.2012.82.05.

12. Almeida CH, Volossovitch A, Duarte R. Penalty kick outcomes in UEFA club competitions (2010-2015): the roles of situational, individual and performance factors. Int J Perform Anal Sport. 2016;16(2):508-522; doi: 10.1080/24748668.2016.11868905.

13. Strafford BW, Smith A, North JS, Stone JA. Comparative analysis of the top six and bottom six teams' corner kick strategies in the 2015/2016 English Premier League. Int J Perform Anal Sport. 2019;19(6):904918; doi: 10.1080/24748668.2019.1677379.

14. Michailidis Y. Analysis of goals scored in the 2014 World Cup soccer tournament held in Brazil. Int J Sport Stud. 2014;4(9):1017-1026.

15. Njororai WSS. Analysis of the goals scored at the 17th World Cup Soccer Tournament in South Korea-Japan 2002. Afr J Phys Health Educ Recreat Dance. 2004; 10(4):326-332; doi: 10.4314/ajpherd.v10i4.24678.

16. Lago-Peñas C, Gómez-Ruano M, Megías-Navarro D, Pollard R. Home advantage in football: examining the effect of scoring first on match outcome in the five 
major European leagues. Int J Perform Anal Sport. 2016;16(2):411-421; doi: 10.1080/24748668.2016.11 868897.

17. Bateman R. Opta's event definitions. Available from: http://optasports.com/news-area/blog-optas-eventdefinitions.aspx.

18. Barreira D, Garganta J, Guimarães P, Machado J, Anguera MT. Ball recovery patterns as a performance indicator in elite soccer. Proc Inst Mech Eng P J Sport Eng Technol. 2014;228(1):61-72; doi: 10.1177/175433 7113493083.

19. Zhao-Q, Zhang H. Analysis of goals in the English Premier League. Int J Perform Anal Sport. 2019;19(5): 820-831; doi: 10.1080/24748668.2019.1661613.

20. Altman DG. Practical statistics for medical research. London: Chapman \& Hall; 1991.

21. Armatas V, Yiannakos A, Sileloglou P. Relationship between time and goal scoring in soccer games: analysis of three World Cups. Int J Perform Anal Sport. 2007;7(2):48-58; doi: 10.1080/24748668.2007.11868 396.

22. Vergonis A, Michailidis Y, Mikikis D, Semaltianou E, Mavrommatis G, Christoulas K, et al. Technical and tactical analysis of goal scoring patterns in the 2018 FIFA World Cup in Russia. FU Phys Ed Sport. 2019;1 7(2):181-193; doi: 10.22190/FUPES190612019V.

23. Jinshan X, Xiaoke C, Yamanaka K, Matsumoto M. Analysis of the goals in the $14^{\text {th }}$ World Cup. In: Reilly T, Clarys J, Stibbe A (eds.), Science and football II. London: Taylor \& Francis; 1993; 203-205.

24. Reilly T. Energetics of high-intensity exercise (soccer) with particular reference to fatigue. J Sports Sci. 1997;15(3):257-263; doi: 10.1080/026404197367263.

25. Bradley PS, Sheldon W, Wooster B, Olsen P, Boanas P, Krustrup P. High-intensity running in English FA Premier League soccer matches. J Sports Sci. 2009; 27(2):159-168; doi: 10.1080/02640410802512775.

26. Catteeuw P, Gilis B, Wagemans J, Helsen W. Offside decision making of assistant referees in the English Premier League: impact of physical and perceptual-cognitive factors on match performance. J Sports Sci. 2010; 28(5):471-481; doi: 10.1080/02640410903518184.

27. Ensum J, Pollard R, Taylor S. Applications of logistic regression to shots at goal in association football. In: Reilly T, Cabri J, Araújo D (eds.), Science and Football V. London: Routledge; 2005; 211-218.

28. Durlik K, Bieniek P. Analysis of goals and assists diversity in English Premier League. J Health Sci. 2014; 4(5):47-56.

29. Yiannakos A, Armatas V. Evaluation of the goal scoring patterns in European Championship in Portugal 2004. Int J Perform Anal Sport. 2006;6(1):178-188; doi: $10.1080 / 24748668.2006 .11868366$.

30. Jones MI, Harwood C. Psychological momentum within competitive soccer: players' perspectives. J Appl Sport Psychol. 2008;20(1):57-72; doi: 10.1080/1041320070 1784841.
31. Olsen E, Larsen O. Use of match analysis by coaches. In: Reilly T, Bangsbo J, Hughes M (eds.), Science and football III. London: Taylor \& Francis; 1997; 209-220.

32. Njororai WWS. Scoring goals. What the coach should know about the timing. Soccer Journal. 2007;November-December:34-36. 